\title{
BREVES CONSIDERAÇÕES ACERCA DO “TEMPO" E DO “ASPECTO” NA LÍNGUA JAPONESA MODERNA
}

Lidia Masumi Fukasawa

Qualquer acontecimento se encontra diante de um processo de mudança que ocorre dentro de um certo "espaço de tempo" ou dentro do "fluir do tempo". Essa consideração coloca-nos, de imediato, diante de, pelo menos, dois problemas que devem ser considerados: o problema do aspecto e do tempo.

Tais problemas se encontram numa relação particularmente estreita e íntima, o que nos permite distinguir-lhes pontos de contacto ou de intersecção. Mesmo ao admitirmos a definição simplista de aspecto como uma categoria que indica a relação entre o processo e o estado (com idéia de duração ou desenvolvimento), e, tempo como uma categoria que indica a localização do processo num dado momento, podemos perceber que "as duas categorias não sã́o (, absolutamente,) exclusivas, coexistindo na mesma forma; assim, "dizia" tanto pode indicar tempo passado quando aspecto durativo. ..". 1

Entretanto, podemos considerar o aspecto como uma categoria de natureza mais objetiva do que a do tempo, na medida em que se relaciona com a idéia de grau de desenvolvimento da ação, isto é, na medida em que se encontra mais interessada no movimento, no modo da ação ou no resultado dessa ação do que propriamente no fluir do tempo. $O$ aspecto é uma realidade gramatical gerada pelo reconhecimento que o falante de uma língua faz com relação ao processo de mudança de um movimento ou o resultado dessa mudança. O tempo, ${ }^{2}$ pelo contrário, é uma categoria de natureza mais abstrata no sentido de que apresenta vinculação mais direta com um "dado momento", e esse "dado momento" é algo abstrato e subjetivo, que, para ser estabelecido ou delimitado, depende de fragmentação e divisão. Fragmentar e dividir o tempo significa dividir em classes a própria compreensão do homem; significa, também, considerá-lo um elemento gramatical divisível em partes, com formas lingüísticas que os determinem. O tempo é um elemento contínuo, sucessivo, infinito e não-fracionável, que parte de um passado infinito para um futuro também infinito; é um elemento totalmente destituído de conteúdo e quem 
lhe atribui o conteúdo é o próprio homem. A diferenciação entre presente, passado e futuro é algo estabelecido pelo homem, com vistas a uma conscientização do "antes" e do "depois" relacionados a cada circunstância do momento presente.

As noções de aspecto e tempo, e suas relaçôes, porém, deverão ser retomadas mais adiante.

É evidente que cada língua exprime de maneira e de formas diferentes um mesmo fato, através dos recursos de expressão de que dispõe. No que concerne ao aspecto e tempo, a Língua Portuguesa dispõe de recursos lingüísticos de expressão bastante ricos e variados. $\mathrm{O}$ aspecto na Língua Portuguesa é, segundo trabalho de Ataliba T. de Castilho, ${ }^{3}$ representando:

a) pelo contexto,

b) pelo sentido próprio do verbo (verbos télicos e atélicos),

c) pela flexão temporal,

d) pelo adjuntos adverbiais,

e) pelos tipos oracionais,

"aflora(ndo) com clareza maior nas formas do indicativo (que exprimem açōes obje tivas - e o aspecto é uma categoria objetiva), rareando no subjuntivo(...)."4 O tempo, levando sempre em conta os pontos de referência (o próprio falante, os fatos narrados em relação a outros fatos e o momento em que se situa o falante), produz os tempos absolutos (presente, passado, futuro), os tempos relativos (imperfeito, mais-que-perfeito, futuro e perfeito do subjuntivo, futuro perfeito) e os tempos históricos ("em que o sujeito se inclui na história, assumindo o papel de "dramatis persona"). ${ }^{5}$

Essa riqueza e variedade de formas lingüísticas (no sentido de categorias gramaticais) da Língua Portuguesa, entretanto, não ocorre na Língua Japonesa, principalmente no que concerne à expressão do tempo. Como recursos lingüísticos que exprimem $o$ aspecto em Língua Japonesa, temos basicamente os "hojoyōguen" ("verbos auxiliares") e o jodōshi ("sufixos verbais").

Kindaichi Haruhiko" divide o aspecto em:

a) aspecto que provém do estado (jōtaisōno asupekuto), que inclui:

1) o aspecto permansivo (Kizentai), expresso por ... te iru, ... te aru, ...ta tokoroda, ...ta.

Ex.: Kowareta tokei. .

/o relógio que está quebrado. . .

2) o aspecto durativo (Shinkotai), expresso por . . te iru, . . te iru tokoroda, . . . te iru tochūda, . . chūda, . . tsutsu aru, ligados a verbos atélicos.

Ex.: Mite iru

/Está vendo/ 
3) o aspecto iminente (Shōzentai) expresso por . . .uto shiteiru, ... tokoroda, ... bakarida.

Ex.: Tokeiga rokujio utouto shiteiru.

/o relógio está para bater as seis horas/

4) o aspecto zero (tanjun jōtaitai): o aspecto que não leva em conta o início ou o fim da ação e que expressa o estado. É expresso por ...te iru e. . .ta

Ex.: Kono michiwa magatte iru.

/Esta rua é torta./

b) aspecto que provém da ação expressa pelo verbo (Dōsasōno asupekuto) que inclui:

1) o aspecto terminativo (Shuketsutai): quando uma ação se realiza totalmente. É expresso . . .te shimau, . . shiowaru, . . .shioeru, ...shikiru.

Ex.: Mite shimau.

/Terminar de ver./

2) o aspecto inceptivo (Shidōtai) expresso por . . .hajimeru, . . .dasu, ...kakeru, (. . kakaru).

Ex.: Kakihajimeru.

/Começar a escrever./

3) o aspecto durativo (Keizokutai) expresso por . . .tsuzukeru, . . .ta, ...te kuru, ...te iku.

Ex: Nijimade matta; sakie iku.

/Fiquei esperando até às duas horas; vou primeiro./

4) aspecto iterativo (Hanpuku keizokutai) expresso por . . .te kuru, ...te iku, ...tsuzuketa e por repetição de termos (mainichi mainichi, kaki kaki, etc.).

Ex.: Jio kaki kakisuru.

/Escreve a letra repetidamente./

Numa análise mais atenta, verificamos que a função gramatical exercida pelo hojōyoguen assemelha-se muito à do jodōshi, daí a necessidade de se analisar mais detidamente o último, não nos esquecendo, porém, de considerá-lo paralelamente com o hojoyōguen.

A noção de semelhança quanto a função gramatical (e o significado que exprimem) éntre hojoyōguen e jodōshi já era proposta pelo gramático Hashimoto Shinkichi:

“(. . .) sono imiya yōhōga jodōshito hotondo onaji monoga arimasu.

"De aru", "te iru", "te irassharu", "te aru", nado. (. . .) "de aru"wa jodōshi "da" to dōguide ari, "te iru", "te irassharu", "te aru" wa 
jodōshi "ta" no aru yōhō ("kaita ji" nadono "ta") to onajide arimasu"."

/há casos em que sua (do hojoyōguen) função e significado são quase idênticos ao do jodōshi: de aru, te iru, te irassharu, por exemplo. (...) De aru é idêntico ao jodōshi da; te iru, te irassharu, te aru possuem a mesma função do jodōshi ta em certos casos (por exemplo, o ta de "Kaita ji" - letra escrita).

Para ele o hojoyōguen se assemelha muito ao jodōshi no sentido de que ambos têm como função gramatical o fato de acrescentar diversos significados ou sentidos ao verbo (tinjutsu). ${ }^{9}$

Nesse sentido, gostariamos de nos referir também à noção de "jodōshi" proposta por Tokieda Motoki como elemento que exprime diretamente a posição do falante em relação a um fato narrado qualquer, isto é, o "tinjutsu" 0 e a de Takeoka Massao, como uma categoria que manifesta não somente o objeto pertencente ao mundo concreto mas, principalmente, a noção subjetiva de interpretação por parte do falante em relação a esse fato concreto. ${ }^{11}$

Em verdade, o jodōshi é uma categoria gramatical que exprime o reconhecimento, o julgamento, a interpretação ou a maneira de pensar do falante. Através dele ${ }^{12}$ (jodōshi) podemos detectar a maneira de apreensão do mundo (modalidade ou asserção) que o falante faz em relação a um determinado "fato narrado" (ou "um processo puro e simples, considerado como desembaraçado de toda intervenção do falante"13 = "dictum"). Em "Ikitai" (Quero ir), é o jodōshi tai (que exprime desejo) que determina a modalidade ("desejo", no caso). Nesse caso, diríamos que "Ikitai" encerra dois sentidos: o sentido próprio do verbo " $I k u$ " (ir) acrescido da vontade do falante em relação a "ir" que é tai (querer). Temos então:

o "dictum" (taishô) + a modalidade ou o subjetivo da interpretação do falante (gengoshutaino ninshikino shikata) $)^{14}$

Essa noação de jodōshi, proposta acima, é de vital importância para ạalisarmos o problema do tempo em Língua Japonesa.

Kindaichi Haruhiko, analisando o tempo gramatical da Língua Japonesa Moderna, ${ }^{1.5}$ apresenta-o como sendo um fato lingüístico expresso em palavras, que contém o antes, o depois ou o durante de um fato. Diz que o que na realidade existe em Língua Japonesa é o "passado" (Kakotai) e o "não-passado" (Hikakotai) e que não temos formas lingüísticas explícitas que exprimam o futuro ou o presente. Assim como faz em aspecto, distingue também o tempo (que para ele é gramatical) passado em tempos que exprimem o estado passado (Jōtaisōno tensu) e os tempos que exprimem a ação no passado (Dōsasōno tensu). Os primeiros equivalem ao passado propriamente dito (Kakotai) e os últimos, à ação concluída (Kanryōtai). Tanto o Kakotai quanto o Kanryōtai 
são expressos pelo jodōshi ta. Embora admita a existência de tempo passado (ta), Kindaichi não admite a de tempo presente ou futuro.

Ora, as três noções de tempo surgem na medida em que as relacionamos entre si, isto $e$, o passado passa a existir no momento em que admitimos o ponto de referência "presente" ou o "futuro" assim como o futuro existe na medida em que admitimos o "presente" ou o "passado". Se, para Kindaichi, o jodōshi $\underline{u}$, you, darō (que indicam suposição ou ação ainda não realizada) não indicam futuro, torna-se difícil concordarmos com ele quando diz que ta indica tempo passado. Na verdade, o jodōshi ta possui a mesma função gramatical de $u, y o u$ ou darỏ (ou qualquer outro jodōshi): exprime a modalidade ou a participação subjetiva do falante em relação a um fato narrado. Diremos, portanto, que o jodōshi ta não é o elemento que exprime o passado. $\mathrm{O}$ que estabelece a idéia real de algo que já aconteceu num passado é o contexto ou às vezes o advérbio de tempo que indica o passado. Assim, no exemplo

Kono isuwa kinōkara kokoni |aru.

/Esta cadeira está aqui desde ontem/

o que indica a açằo de aru (estar, existir) no passado ou como ação concluída é a expressão "kinōkara" (desde ontem). Não é necessário que se utilize, nesse exemplo, o jodōshi ta para se exprimir a ação concluída ontem de aru. 0 jodōshi tă, em outras palavras, não é um elemento gramatical que indica o passado. Ele indica, sim, a participação subjetiva do falante em relação ao fato narrado. Em

Sōsō, kyōwa bokuno tanjōbidatta .

/É mesmo! Hoje é o dia do meu aniversário!/

o jodōshi tạ tem a função de um "kandōshi" (partícula que encerra modalidade - surpresa). Da mesma forma, os jodōshi que poderiam normalmente ser considerados como elementos gramaticais que exprimem a ação não concluída, são na realidade, elementos que indicam apenas a modalidade. Vejamos, na frase abaixo, a função de darō, por exemplo:

Amega furudarō.

/Parece que vai chover./

A idéia de dúvida indicada pelo jodōshi darô constitui a modalidade "suposição" expressa pelo falante, isto é, trata-se da participação ou interpretação do falante em relaçã̃o ao fato "Amega furu" (Chover). O jodōshi darō é a forma que indica o sentimento de dúvida que paira no espírito do falante.

A idéia de presente, passado ou futuro relaciona-se diretamente com a posição ou 0 momento em que se encontrar o emissor da mensagem com relação ao fato que este narra. Relaciona-se com a situação da enunciação. 
Em língua japonesa, a idéia de presente, passado ou futuro encontra-se vagamente configurada na mente do falante e daquele que interpreta o enunciado proposto por aquele. Essa divisão ou delimitação de tempo presente, passado ou futuro não é nítida a ponto de requerer formas gramaticais expressas que as tornem "categorias gramaticais". Quando dizemos

Yoshi, katta

/Bom, comprarei/

o ta contém apenas o sentido de decisão com relação à ação | de comprar (kau). $\mathrm{O}$ mesmo ocorre em

\section{Sā, doita doita}

/Bem, saiam, saiam! (abram alas)/.

Pensamos, pois, que mesmo o jodōshi ta $\underline{a}$ não é elemento indicador de tempo verbal. Ele está, antes, intrinsecamente relacionado com a idéia de modalidade ou de interpretação que o falante faz do fato narrado. Essa função encontra-se ligada à própria natureza do jodōshi como elemento subjetivo que parte do falante. Podemos, portanto, admitir a hipótese de que a língua Japonesa constitui uma das línguas que não possuem o tempo considerado como gramatical e verbal - pelo menos, não com a mesma conceituação de tempo verbal contida na Língua Portuguesa.

Como vimos, a Língua Japonesa é rica em termos de expressões ou formas lingüísticas gramaticais que exprimem $o$ aspecto, o que não ocorre com $o$ tempo verbal. $O$ aspecto existe como uma categoria gramatical. O tempo existe como um fato lingüístico, isto é, não como uma categoria gramatical, mas somente na medida em que exprime as indicaçбes cronológicas contidas no aspecto. Ele (o tempo) é "um elemento interior ao predicado ou à frase de sentido completo e só existe no sentido de que "comporta um certo modo de manifestação no tempo de uma ação ou qualidade; é a indicação da maneira como elas preenchem o período a que a enunciação diz respeito", ${ }^{16}$ isto é, ela existe no aspecto. Não se encontram, em Língua Japonesa, formas gramaticais que exprimam as indicações cronológicas propriamente ditas, nem as divisðes ou fragmentaçðes do tempo em presente, passado e futuro.

Se o tempo é uma categoria abstrata, acrescentar uma forma gramatical ao fato para se expressar o tempo é algo que não é racional. É porisso que a Língua Japonesa é tão pobre em expressar o tempo. O próprio tempo é algo infinito e não cortável em partes (presente/passado/futuro) e o predicado não precisa necessariamente estabelecer ou expressar a divisão do tempo. A distinção entre presente, passado e futuro é, para o homem, a divisão de algo que não é divisível. Fragmentar o tempo não é uma atividade nada logica, 
e portanto, difícil de gerar formas estanques e finais. O tempo não é algo que possua uma estruturação mecânica e objetiva a ponto de ser fragmentado e capaz de gerar formas gramaticais explícitas e enumerativas (ou sucessivas que venha um após o outro). O sistema do tempo gramatical é construído de acordo com classificaçðes categoriais sutis, subjetivas e porisso, diferentes de língua para língua. A diferenciação entre presente, passado e futuro não é nada objetiva. Nos dois exemplos abaixo

\author{
Hora, denshaga kuru. \\ /Olha, lá vem o trem/ \\ Hora, denshaga kita. \\ /Olha, chegou o trem/,
}

o sentido de futuro ou passado encontra-se intrinsecamente ligado com a própria atitude mental do falante e do receptor da mensagem. Ambos podem ser interpretados como fatos que ocorrem tanto como ação concluída ou como ação que vai acontecer (futuro ou passado).

\title{
Harerudarō \\ /Provavelmente vai fazer bom tempo/
}

possui um conteúdo cujo sentido pode ser interpretado como sendo futuro, mas não podemos ver na frase nenhuma forma gramatical expressa que indique futuro. $O$ sentido de futuro está na cabeça do falante e expressa pelo próprio contex to de situação ou pelo sentido geral da frase.

\section{Jio kaiteiru \\ /Está escrevendo a letra/}

expressa a duração da ação de escrever e não o tempo verbal.

Se o tempo é uma categoria abstrata, indivisível, e de caráter infinito, estabelecer-lhe divisőes (em presente/passado/futuro) significa tentar dividir em categorias formais o próprio pensamento do homem. E por esta razão que $o$ falante de língua Japonesa sente dificuldades em distinguir o tempo verbal (da Língua Portuguesa). Seu modo de raciocínio não é tăo lógico-matemático como o pretendem os falantes da Língua Portuguesa. Embora não possuindo a riqueza na variedade de tempos e modos verbais, o japonês consegue se expressar e se comunicar plenamente na medida de todas as suas necessidades enquanto homem. Para uma comunicação ampla e definitiva, não é necessário que se estabeleçam os parâmetros (que são na realidade controvertidos) que delimitem a extensão do presente, do passado e do futuro. O tempo é uma categoria que não se deixa descrever por meio das classificaçðes grama- 
ticais porque é um elemento que transcende o enunciado enquanto indicação em formas lingüisticas expressas.

A Língua Japonesa, portanto, é rica em recursos expressivos (e em formas gramaticais) que dizem respeito ao aspecto porque este constitui a descrição de um "estado de coisas", mas é parca em recursos que exprimem o tempo porque este é uma categoria abstrata, difícil de ser dividida em partes.

Notas

1 - Ataliba T. de Castilho - "introdução ao Estudo do Aspecto Verbal na Língua Portuguesa", in Revista Alfa, n? 12. Marília, FFCL de Marília set. de 1967, p.116.

2 - Tomamos aqui a noção de "tempo" não como a de tempo gramatical (ou tempo verbal = "tense" do Inglês) propriamente dita, mas mais no plano existencial ou semântico.

3 - Ataliba T. de Castilho, p.108.

4 - Idem, p.16.

5 - Idem p.16.

6 - Para se expressar o tempo ou o aspecto encontramo-nos, na realidade, diante de duas possibilidades, em Língua Japonesa: ou se acrescenta um elemento que se relaciona com o processo ou movimento do fato a ser descrito, através de um contexto de situação (o que pode ser detectado pelo sentido que provém da relação entre todos os elementos da frase e a situação de enunciação) ou através de uma forma gramatical ou lexical (jodóshi, expressões que indicam tempo, etc.).

7 - Kindaichi Haruhiko - Nishongo Dōshino Asupekuto. Tóquio, Ed. Muguishobō, 1976, pp.39-55. 146-147.

8 - Hashimoto Shinkichi - Shinbunten Bekki. Tóquio, Ed. Tozanbō 1938, pp.

9 - "tinjutsu": "modalidade" ou "asserção" (interpretação que o falante faz em relação ao fato considerado em si só, isto é, ao "tema do aoristo").

10 - Idem.

11 - Takeoka Masso - "KIto KERIno Imi Yohō", in Revista Bunpō. Tóquio, Ed. Meijishoin, 1970, pp.46-55.

12 - Evidentemente, não é somente através do jodōshi que podemos detectar a modalidade em Língua Japonesa, mas também através de outros recursos lingüísticos como: a) a escolha ou seleção das palavras, b) a ordem dessas palavras, c) o te-ni-o-ho (partículas relacionais que indicam função sintática) d) contexto, e) gênero do texto. Além desses fatores, o jodōshi, o katsuyōkei (formas de flexão), ou kandōshi (interjeição) e o setsuzokushi (conjunção) são termos que mais diretamente exprimem a modalidade. cf. Takeoka Massao, pp. 46-55. 
13 - Noção de "Modalidade" proposta por Bally, apud Dicionário de Linguística - Jean Dubois et allii. SP, Cultrix, 1978, p.413.

14 - Takeoka Masao, pp.46-55

15 - Kindaichi Haruhiko, pp.29-61

16 - T. Todorov e O Ducrot - Dicionário Enciclopédico das Ciências da Linguagem. SP, ed. Perspectiva, 1977, p.292.

\section{BIBLIOGRAFIA}

CASTILHO, Ataliba T. de "Introdução ao Estudo do Aspecto Verbal na Língua Portuguesa", in Revista Alfa. Marília, FFCL de Marília, 1967, pp.13-117.

DUBOIS, Jean et allii - Dicionário de Lingǘstica. SP, Cultrix, 1978.

HASHIMOTO, Shinkichi - Shinbunten Bekki. Tóquio, Ed. Tozanbō, 1938.

HASHIMOTO, Shinkichi - Shinbunten Bekki. Tóquio, Ed. Muguishobō, 1976.

HOJO, Tadao - "Iwayuru kakono jodōshi towa", in Revista Bunpo, vol. 2, Tóquio, Maio de 1969, pp.10-21.

KAZAMA, Rikizo - "Te iru no iikata", in Revista Kokugoto Kokubungaku, vol. 32. Tóquio, março de 1955, pp.48-58.

KINDAICHI, Haruhiko - Nihongo Dōshino Asupekuto, Tóquio, Ed. Muguishobō, 1976.

MATSUMURA, Akira - Nihon Bunpō Jiten. Tóquio, Ed. Meijishoin, 1971.

TAKEOKA, Massao - "Keri to Ki no imi, yoho, in Revista Bunpō, no 5. Tóquio, Ed. Meijishoin, maio de 1970.

TODOROV, T. e DUCROT, O. - Dicionário Enciclopédico das Ciências da Linguagem. SP, Ed. Perspectiva. 1977.

TOKIEDA, Motoki et allii - Kokugogaku Jiten. Tóquio, Ed. Tokyoto, 1971.

TOKIEDA, Motoki - Nihon Bunpō Kögohen. Tóquio, Ed. Iwanami, 1968, 21 a ed.

SUZUKI, Tanjiro - "Dōshino Mondaiten", |in Nihon Bunpōkōza-Hinshibetsu. Tóquio, Meijinshoin, 1972, pp.143-177.

WATANABE, Minoru - Kokugo - Kobunron.| Tóquio, Ed. Hanawashobō, 1971.

YAMADA, Yoshio - Nihon Bunpōgaku gairon. Tóquio, Ed. Hōbunkan, 1967, 7ª ed. 